\title{
Regulatory peptides: key factors in the control of bodily functions
}

\author{
JULIA M POLAK, S R BLOOM
}

At the turn of the century Pavlov postulated the theory of "nervism," while Brown-Séquard put forward the idea that certain tissues of the body can release active substances capable of specifically affecting distant organs. BrownSéquard's theory of "chemical messengers" was further supported by Bayliss and Starling, who in 1902 reproduced Pavlov's experiments on pancreatic secretion using extracts of denervated duodenum. In one afternoon Pavlov's Nobel prize winning ideas of neural control of bodily functions were swept away. Bayliss and Starling then proposed the word "hormone" (from the Greek word for "I arouse to activity") to describe the existence of blood borne chemical messengers acting at a distance.

These two apparently antagonistic views, neural versus hormonal control of bodily functions, have recently been reconciled with the discovery that the same active principles (that is, regulatory peptides) can be produced and released by both endocrine and neural tissues and may act as circulating hormones, local regulators, neurotransmitters, or all of these. The term "regulatory peptide" has recently been proposed to describe active peptides capable of eliciting their effects in one or more of these three separate ways.

\section{Characteristics of regulatory peptides}

Secretin was discovered in 1902 and gastrin in 1905, but most of the regulatory peptides have been discovered since the 1960s. Though all these regulatory peptides were found first in the gut or brain or both, these peptides are now known to be present in every tissue of the body. The table summarises the main chemical characteristics, distribution, and mode of action of the best known regulatory peptides. Some of the general characteristics of the most widely distributed regulatory peptides are given below.

\section{Vasoactive intestinal polypeptide}

Sami Said, a pulmonary physician working in Texas, postulated the existence and release of a vasoactive hypotensive substance when he noted that patients with pulmonary embolism developed definite hypotension. At that time (the 1960s) techniques for the extraction of active peptides were available in the department of chemistry of the Karolinska Institute in Stockholm. Said was able to extract from the

Mammalian regulatory peptides*

\begin{tabular}{|c|c|c|c|c|}
\hline Peptide & Main distribution & Established actions & $\begin{array}{l}\text { Proposed mode } \\
\text { of action }\end{array}$ & $\begin{array}{l}\text { Sequence similarities } \\
\text { with other peptides }\end{array}$ \\
\hline $\begin{array}{l}\text { Gastrin } \\
\text { Cholecystokinin }\end{array}$ & Gut Gut, brain & $\begin{array}{l}\text { Stimulates gastric acid secretion } \\
\text { Stimulates contraction of gall bladder and secretion of } \\
\text { pancreatic enzymes }\end{array}$ & $\begin{array}{l}\text { Endocrine } \\
\text { Endocrine and } \\
\text { neurotransmitter }\end{array}$ & $\begin{array}{l}\text { Cholecystokinin } \\
\text { Gastrin }\end{array}$ \\
\hline Secretin & Gut & Stimulates secretion of pancreatic bicarbonate & Endocrine & $\begin{array}{l}\text { Glucagon, VIP, GIP, } \\
\text { peptide histidine } \\
\text { isoleucine }\end{array}$ \\
\hline Glucagon and enteroglucagon & Pancreas, gut, brain & $\begin{array}{l}\text { Regulates carbohydrate metabolism (pancreatic glucagon). } \\
\text { Trophic to gut (enteroglucagon) }\end{array}$ & $\begin{array}{l}\text { Endocrine and } \\
\text { neurotransmitter }\end{array}$ & $\begin{array}{l}\text { Secretin, VIP, GIP, peptide } \\
\text { histidine isoleucine }\end{array}$ \\
\hline $\begin{array}{l}\text { Gastric inhibitory } \\
\text { polypeptide (GIP) }\end{array}$ & Small intestine & $\begin{array}{l}\text { Stimulates secretion of insulin. Inhibits secretion of } \\
\text { gastric acid }\end{array}$ & Endocrine & $\begin{array}{l}\text { Secretin, glucagon, VIP, } \\
\text { peptide histidine } \\
\text { isoleucine }\end{array}$ \\
\hline $\begin{array}{l}\text { Vasoactive intestinal } \\
\text { polypeptide (VIP) }\end{array}$ & $\begin{array}{l}\text { Central and peripheral } \\
\text { nervous system }\end{array}$ & Stimulates muscle relaxation, vasodilation, secretion & Neurotransmitter & $\begin{array}{l}\text { Secretin, glucagon, GIP, } \\
\text { peptide histidine } \\
\text { isoleucine }\end{array}$ \\
\hline Motilin & Small intestine & Stimulates gut motility & Endocrine & Not known \\
\hline Pancreatic polypeptide & Pancreas & $\begin{array}{l}\text { Inhibits pancreatic enzyme secretion and gall bladder } \\
\text { contraction }\end{array}$ & Endocrine & $\begin{array}{l}\text { Peptide tyrosine/tyrosine, } \\
\text { neural peptide tyrosine }\end{array}$ \\
\hline Somatostatin & $\begin{array}{l}\text { Gut, pancreas, thyroid, } \\
\text { brain }\end{array}$ & $\begin{array}{l}\text { Inhibits release and action of many peptides (? } \\
\text { antagonistic to bombesin) }\end{array}$ & $\begin{array}{l}\text { Endocrine, paracrine, } \\
\text { neurotransmitter }\end{array}$ & Fish urotensin II \\
\hline Substance $P$ & $\begin{array}{l}\text { Central and peripheral } \\
\text { nervous system }\end{array}$ & Sensory, vasodilatory. Stimulates muscle contraction & Neurotransmitter & Bombesin \\
\hline Bombesin & Gut, brain, lung & $\begin{array}{l}\text { Stimulates release of peptides (? antagonistic to } \\
\text { somatostatin) }\end{array}$ & $\begin{array}{l}\text { ? Paracrine, } \\
\text { neurotransmitter }\end{array}$ & Substance $\mathbf{P}$ \\
\hline Neurotensin & Gut, adrenal, brain & Vasodilatory. Inhibits gastric acid secretion & $\begin{array}{l}\text { Endocrine, } \\
\text { neurotransmitter }\end{array}$ & Amphibian xenopsin \\
\hline Enkephalin & $\begin{array}{l}\text { Gut, brain, sympathetic } \\
\text { nervous system, } \\
\text { carotid body, adrenal }\end{array}$ & Opiate & $\begin{array}{l}\text { ? Endocrine, } \\
\text { neurotransmitter }\end{array}$ & $\begin{array}{l}\text { Belongs to large family of } \\
\text { opioid peptides }\end{array}$ \\
\hline
\end{tabular}

- Only well established peptides originally extracted from brain and gut are shown in table.

(Table adapted from table $11 \cdot 1$ in Polak and Bloom. ${ }^{3}$ ) 
gastrointestinal tract a very potent vasoactive substance, subsequently termed vasoactive intestinal polypeptide (VIP), which was later characterised as a 28 amino acid peptide and found to belong to a family of peptides which includes VIP, gastric inhibitory polypeptide (GIP), secretin, peptide histidine isoleucine (PHI), and glucagon.

VIP is widely distributed in almost every part of the body and is localised to autonomic nerves. In certain instances the peptide has been reported to coexist with the classical neurotransmitter acetylcholine but is usually present in the so called "non-adrenergic, non-cholinergic" component of the autonomic nervous system. VIP has potent vasodilatory, smooth muscle relaxant, and secretory properties. VIP nerve fibres originate mostly from local neuronal cell bodies, which, though connected to the central nervous system both anatomically and functionally, act largely in an independent manner. Once VIP was found to be present in nerves, the question arose whether it (and other peptides present in nerves) may be acting as a neurotransmitter. The rigid criteria applied by neuroscientists to define a substance as a neurotransmitter proved impracticable in the case of regulatory peptides localised in nerves. This was mainly due to the fact that peptides are much larger molecules than classical neurotransmitters and that, once released, they probably travel for much longer distances. In addition, they appear not to be removed by reuptake in nerve terminals. Nevertheless, the local concentration of VIP rises after parasympathetic nerve stimulation, and the rise parallels several atropine resistant tissue responses such as vasodilation of the gastric, nasal, and salivary glands. These tissue responses may be mimicked by microinjection of VIP into the local circulation and can be blocked by specific antibodies to VIP.

\section{Substance $\mathbf{P}$}

Fifty two years ago Von Euler and Gaddum, working in Dale's laboratory in Hampstead, noted the release of a substance after vagal stimulation which was capable of eliciting an atropine resistant contraction of muscle in the gut. The anomalous finding of a tissue response after nerve stimulation which could not be prevented by the classical nerve blockers was unexpected and challenged the view of a bipartite division of the autonomic nervous system, each branch of which was blockable by known compounds. The substance was further purified and it was given the non-committal name of substance $P$ (for powder). Later on, substance $P$ was characterised as an 11 amino acid peptide with actions including contraction of non-vascular smooth muscle and vasodilation. Substance $P$ was thought possibly to play some part in sensory responses after Otsuka in Japan had reported its presence in the dorsal root ganglion and after Thomas Hökfelt in Stockholm had located substance P like immunoreactivity in a subclass of primary sensory neurones. Further support for the presence of substance $P$ in sensory neurones has recently been given by the finding of an appreciable depletion of substance $P$ from sensory $C$ fibres after treatment of animals with capsaicin, a pungent extract of red pepper. This explains the old wives' tale of local application of red pepper as a palliative for toothache.

Substance $P$ belongs to a family of peptides which includes physalaemin and eledoisin-two peptides found in amphibians and an octopus but not in mammals. Mammals have, however, two separate receptors to substance $P$, one of which reacts best with eledoisin (E type) and the other with physalaemin ( $\stackrel{\text { W }}{\frac{0}{2}}$ type), and this may suggest the possible existence of an eledoisin or physalaemin like peptide in mammals. Substance $c$ $P$ is very widely distributed. The nerve fibres containing $\widehat{\widehat{O}}$ substance $P$ often originate from neuronal cell bodies located $\bar{F}$ outside the tissue they innervate. These cell bodies are mainly found in sensory ganglia or centres including the dorsal root $\mathrm{m}$ ganglia, nodose ganglia, and trigeminal nucleus.

\section{Cholecystokinin/pancreozymin}

In 1928 Ivy and Oldberg coined the name cholecystokinin $\stackrel{\vec{D}}{\stackrel{2}{2}}$ to describe the active principle responsible for the contraction $⿻$ of the gall bladder. Some 15 years later, and independently $\overrightarrow{0}$ from Ivy's work on cholecystokinin, Harper and Raper showed that intestinal extracts stimulated secretion of pan- $\vec{\omega}$ creatic enzymes and named their active factor pancreozymin. $\frac{5}{3}$ Subsequently, Jorpes and Mutt at the Karolinska Institute, Stockholm, showed that these active principles (cholecystokinin and pancreozymin) were one and the same regulatory peptide capable of eliciting both contraction of the gall bladder and secretion of pancreatic enzymes.

This regulatory peptide is now commonly known as $\vec{f}$ cholecystokinin or CCK. Cholecystokinin belongs to the $\vec{\circ}$ gastrin-cholecystokinin family of peptides. Like most other $\underset{\checkmark}{\checkmark}$ regulatory peptides, cholecystokinin is present in many $\vec{z}$ molecular forms, all of which have in common the last eight amino acids at the $\mathrm{C}$ terminal, with variable extensions at their $\overrightarrow{0}$ $\mathrm{N}$ terminals (commonly 33, 39, and 58 amino acids in length). The actions of these variants of cholecystokinin go far beyond the original description of the actions of the peptide in the digestive system. Possibly cholecystokinin acts both as a circulating hormone and as a neurotransmitter. Some of the evidence for this variable mode of action is supplied by the $\frac{\curvearrowright}{\otimes}$ immunocytochemical detection of cholecystokinin like material $\stackrel{\varrho}{\rightleftarrows}$ in endocrine cells, principally of the intestinal mucosa, and in $\frac{O}{3}$ central and peripheral nerves. Cholecystokinin has recently been shown probably to act as a neurotransmitter, particularly in the central nervous system.

\section{Somatostatin}

Somatostatin was originally discovered in the hypothalamus 윽 during the search for a factor capable of inhibiting the release $N$ of growth hormone. A "growth hormone release inhibiting $\underset{D}{\sigma}$ factor" or somatostatin was described in 1973, winning for its discoverers the Nobel prize. It was later found to be much more widely distributed in the body and to inhibit the release of a wide range of hormones. Somatostatin was also found to have a direct action on the hormone effector tissue, making it one of the most powerful inhibitory substances yet discovered. Somatostatin was originally described as a 14 amino acid $\stackrel{\infty}{+}$ peptide, but larger molecular weight peptides extending $\underset{T}{T}$ beyond the $\mathrm{N}$ terminal have now been found-in particular a $\stackrel{\mathbb{1}}{\mathrm{D}}$ 28 amino acid peptide which has an even more potent inhibitory action and longer half life.

Somatostatin is localised both in mucosal endocrine cells and in autonomic nerves and is thus likely to act as a local or $\delta$ circulating hormone and as a neurotransmitter/neuromodulator. Large concentrations of somatostatin have been found in $\frac{\overline{0}}{2}$ the gastrointestinal tract and pancreas as well as in the thyroid and other peripheral organs. 


\section{Bombesin}

Mammalian bombesin (also known as gastrin releasing peptide) is a 27 amino acid peptide which has considerable sequence homologies (seven amino acids at the $\mathrm{C}$ terminal) with a closely related regulatory peptide found in the skin of the discoglossid frog, Bombina bombina-hence its name. Substantial concentrations of bombesin are found in the brain, the gastrointestinal tract and pancreas, and the respiratory tract. Bombesin is a potent releaser of most regulatory peptides and thus acts in opposition to somatostatin. In addition, bombesin is a potent trophic factor, as has recently been shown for the pancreas and the respiratory tract.

\section{Opiate peptides}

A good example of a large family of peptides with a close sequence relation is the group of opiate peptides. Since the seminal discovery in Britain in 1975 by Hughes and Kosterlitz of two pentapeptides of the opiate family reacting with specific brain receptors the family has grown to an extraordinary size. It is beyond the scope of this review article to describe the characteristics of each individual opiate peptide, a topic well reviewed in a recent issue of the British Medical Bulletin. ${ }^{1}$ Opiate peptides are found not only in the brain and gastrointestinal tract but also in most other tissues-in particular, the sympathetic chain and the adrenal medulla. The very abundance of these peptides in sympathetic nervous tissue and in particular in the adrenal medulla allowed biochemists to uncover the larger precursor forms and to characterise the several messenger RNAs directing their synthesis. The concept of gene reduplication in evolution resulting in divergent systems is nowhere better seen.

\section{Peptide with histidine isoleucine}

This peptide of 28 amino acids is one of the recent discoveries from the Karolinska Institute. Tatemoto and Mutt's work on the chemical characterisation of peptides led recently to the discovery of three further peptides, one of which is a peptide with histidine at the $\mathrm{N}$ terminal end and isoleucine at the $\mathrm{C}$ terminal end and so is termed PHI. This peptide belongs to the VIP/glucagon/secretin family of peptides. It shares more than half of its amino acids with VIP, and its very similar distribution and localisation in indistinguishable nerve fibres invites speculation on the existence of a single precursor hormone capable of giving rise, by internal gene duplication, to two separate regulatory peptides, PHI and VIP.

\section{Peptide tyrosine/tyrosine and neuropeptide with tyrosine}

Peptide tyrosine/tyrosine (PYY) is another of the recent discoveries originated by the use of the new technique at the Karolinska Institute. PYY is present in large quantities in the gastrointestinal tract and is localised by immunocytochemistry to mucosal endocrine cells in the ileum and colon. A closely similar peptide found at the same time as PYY is neuropeptide $\mathrm{Y}$, so called because of the tyrosine residue at both the $\mathrm{N}$ and $\mathrm{C}$ terminal ends. NPY is very widely distributed in neural tissue.

\section{How the regulatory peptides are localised}

Once a regulatory peptide is found, we need to know its localisation, how much of it is found in each tissue, and which tissue components are responsible for its manufacture and release. Two techniques which have been used for this purpose are radioimmunoassay and immunocytochemistry. Both use specific antibodies to regulatory peptides. Despite the frequency of families of peptides with closely related amino acid sequences antibodies can be made with different immunoreactivity, capable of recognising specific non-common areas of related peptide molecules. These antibodies are used either in a radioimmunoassay system (to obtain information on the precise quantity and molecular form of a peptide, both in fluids and in tissues) or in an immunocytochemical system (to provide information about the localisation of the peptide in particular tissue structures-cells or nerves).

Technical details of specific radioimmunoassays for many regulatory peptides and various immunocytochemical techniques and their applications have already been published. Two additional interesting new variations have been developed.

Firstly, the entire regulatory peptide containing system or diffuse neuroendocrine system can now be visualised. This technique is based on the discovery in the 1960s of a subclass of a glycolytic enolase enzyme which was present in very large concentrations in the brain and was localised exclusively to neurones-neurone specific enolase. Using antibodies to neurone specific enolase Paul Marangos and his colleagues at the National Institutes of Health, Bethesda, were able specifically to immunostain all neural tissue and also endocrine cells of the adrenal medulla, the pancreatic islets, the pituitary, and interfollicular $\mathrm{C}$ cells of the thyroid. Antibodies to neurone specific enolase were thus able to immunostain the entire diffuse neuroendocrine system composed of peptide producing endocrine cells and autonomic and sensory nerves. Comparative studies using antibodies to specific regulatory peptides indicated that the mass of this diffuse neuroendocrine system is considerably larger than the sum of the individual components so far characterised by the production of a given regulatory peptide, thus indicating that there are still a few endocrine cells and nerves whose peptide products await discovery.

Secondly, gold particles, which are electron dense and thus visible with the electron microscope, can be made in different sizes by certain chemical procedures. They can then be readily attached to antiboaics. This procedure has proved to be very useful for the location with the electron microscope of regulatory peptides within intracellular organelles of endocrine cells and nerves, hitherto impossible.

\section{Individual organ systems}

\section{GASTROINTESTINAL TRACT}

The regulatory peptide system of the gastrointestinal tract has received particular attention as many of the regulatory peptides were first discovered in the gut, a particularly rich source. Different regulatory peptides are present in all areas and layers of the gastrointestinal tract from oesophagus down to the rectum. Their distribution, however, is quite precisein particular, the distribution of mucosal peptides with hormone actions. These peptides, localised in endocrine cells sparsely distributed among non-endocrine mucosal cells, show a preferential area of distribution (fig 1). Several regulatory peptides are localised exclusively either in mucosal endocrine 


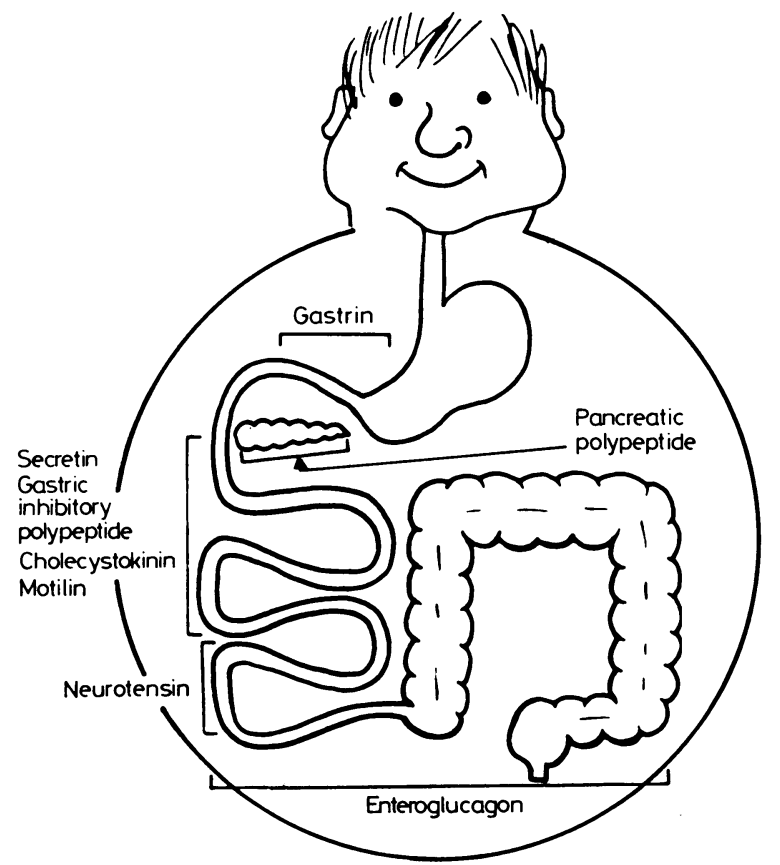

FIG 1-Distribution of regulatory peptides in gastrointestinal tract. (Taken from Bloom and Polak. ${ }^{2}$ )

cells or in enteric nerves, whereas others show a dual localisation.

A specifically immunostained mucosal endocrine cell has a characteristic appearance. Many cells are triangular with a narrow end directed towards the lumen of the bowel and terminating in specialised microvilli; the broad base often extends for several millimetres along the mucosa and is in contact with blood vessels (fig 2). Ultrastructurally, each type of endocrine cell also shows several characteristic features; in particular, the secretory granules have distinctive size, density, limiting membrane, and halo characteristics.

The peptidergic neuronal system (fig 2) is organised in a complex network composed of different subclasses of peptidergic neurones each supplying specific structures within the gut wall. Most of these enteric nerves originate from local cell bodies which are localised in two ganglionated plexuses; one, the submucous, lies just under the mucosa, while the other, the myenteric plexus, is found between the longitudinal and circular muscle coat. These peptide containing neuronal cell bodies can act independently producing, for example, complex coordinated gut movements. Thus gut completely isolated from the body still shows peristalsis and can propel its luminal contents. None the less, the plexuses are functionally and anatomically related to the nervous system outside the gut wall and are influenced by the higher centres. Enteric nerves containing peptides belong to the "non-adrenergic, noncholinergic" subdivision of the autonomic nervous system, which has been shown to be highly heterogeneous. With antibodies labelled with gold to a variety of regulatory peptides including VIP, substance $P$, somatostatin, and the enkephalins, these peptide containing nerves may be subdivided into their various subclasses.

Classical hormones are localised in endocrine glands, but the newly found regulatory peptides are mainly contained in endocrine cells and nerves intermingled with tissue structures with no neuroendocrine activity. The classical means of investigating endocrine function-removing an endocrine gland to show deficiency syndromes or by giving excessive gland extract to assess the results of overactivity-cannot be easily applied to this diffuse neuroendocrine system. The physiological actions of these regulatory peptides are thus far more difficult to work out, but the task has been helped by their purification, allowing observation of the effect produced by infusions of pure peptides into the circulation. Another route to understanding is the clinical observation of patients with an excess or deficiency of a particular regulatory peptide. The best examples are the syndromes associated with excessive peptide production by tumours-for example, the vipoma syndrome, previously included in the Verner Morrison syndrome or watery diarrhoea hypokalaemia achlorhydria or WDHA syndrome. This is characterised by the development of intractable watery diarrhoea due to excessive intestinal secretion leading to hypokalaemia and is caused by massive quantities of VIP in the circulation. Abnormalities of gut peptide hormones have also been shown in many other diseases, and have proved to be useful indicators of the specific anatomical area of the bowel affected by the disease.

Diseases which affect the ganglionated plexuses of the bowel have been shown to affect their contained peptides. Diseases with considerable damage or absence of neuronal cell bodies, such as that seen in Hirschsprung's disease (a congenital abnormality of the neural plexus) or in Chagas' disease (an acquired condition) show a considerable depletion of their peptide content, including that of VIP, substance $P$, somatostatin, bombesin, and the enkephalins, and these disorders are characterised by intractable chronic constipation.

In Crohn's disease the enteric nerves containing VIP are

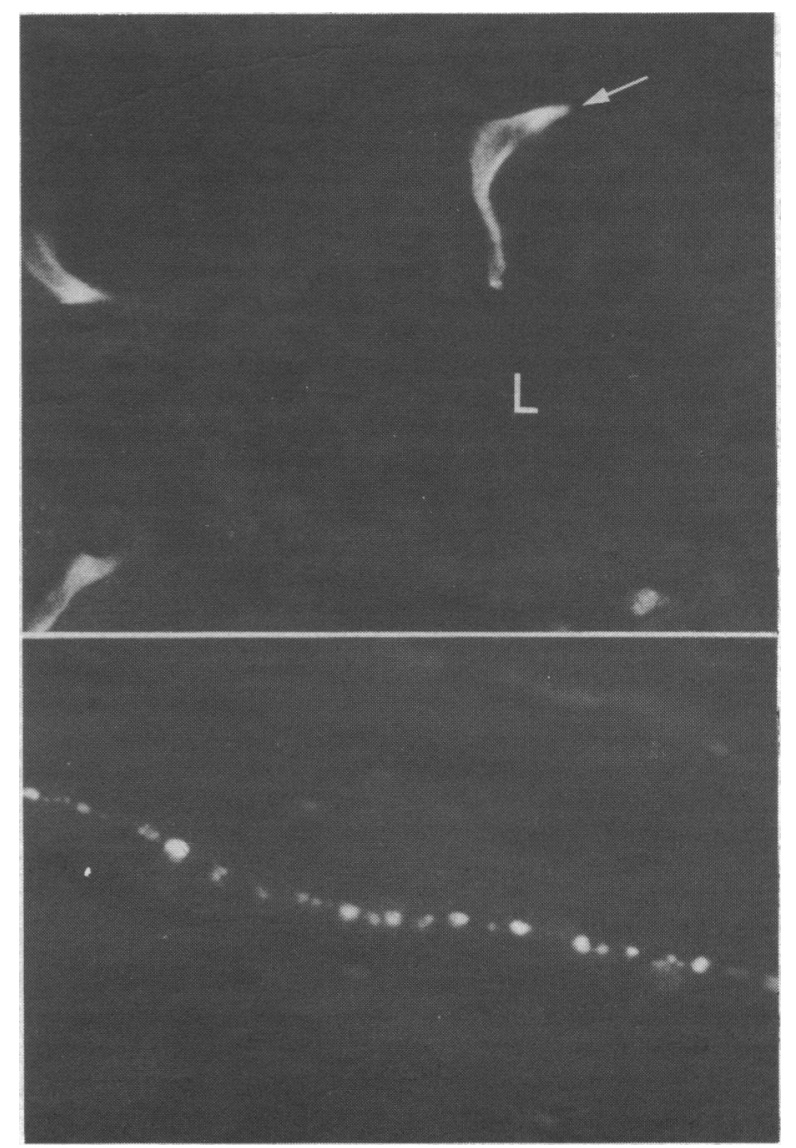

FIG 2-Top: Endocrine cells of human colon. Note connection with lumen (L) and basal cytoplasmic extension (arrow). Bottom: Nerve of human bowel containing vasoactive intestinal polypeptide. Note presence of classic varicosities. 
obviously hyperplastic, distorted, and abnormal. These changes are not seen in patients with ulcerative colitis or other types of inflammatory bowel disease. In Crohn's disease the abnormalities of the VIPergic nerves are particularly noticeable in the mucosal layers of the bowel. This has led to the suggestion that investigations of the VIP content and morphology of the VIPergic nerves in endoscopic biopsy specimens of patients with a variety of inflammatory bowel diseases and other complaints might be a useful investigative tool for the diagnosis of Crohn's disease. This proved to be so in a blind study of more than 100 patients.

\section{CENTRAL NERVOUS SYSTEM}

More than 15 regulatory peptides have been found to be present in the brain, frequently in separate systems of cell bodies. These project to various brain areas in newly recognised peptidergic pathways. The hypothalamus is particularly rich in regulatory peptides. The limbic system (hippocampus and amygdala, the area of the brain most concerned with emotion, memory, and sexual drive) also contains a wide variety of regulatory peptides. Some peptides are found within local cell bodies in the brain cortex and contain, for example, VIP, cholecystokinin, and NPY.

Regulatory peptides have been shown to be abnormally distributed in several brain diseases, including Alzheimer's disease or senile dementia (decrease of cortical somatostatin), Huntington's chorea (reduction of substance $P$ and cholecystokinin in the striatum), and schizophrenia associated with withdrawal symptoms (decrease of somatostatin and cholecystokinin in hippocampus).

The spinal cord also contains a wealth of regulatory peptides, including substance $\mathrm{P}$, somatostatin, neurotensin, VIP, cholecystokinin, the enkephalins, oxytocin, neurophysin, adrenocorticotrophic hormone, bombesin, angiotensin, thyrotrophin releasing hormone, and NPY. All these peptides, with the exception of thyrotrophin releasing hormone, are found in both the dorsal and ventral horns, and they originate from three different sources-from primary sensory neurons in the dorsal root ganglion (substance $\mathrm{P}$, somatostatin, VIP, and cholecystokinin); from intrinsic cell bodies of the spinal cord (enkephalin, neurotensin, NPY, and possibly oxytocin, neurophysin, adrenocorticotrophic hormone, and bombesin); and from cell bodies localised in the upper regions of the spinal cord or basal ganglia of the brain, forming descending peptidergic pathways.

\section{RESPIRATORY TRACT}

At least six regulatory peptides have been found to be present in the respiratory tract. These include, in man, VIP, substance P, bombesin, PHI, and calcitonin. Somatostatin and cholecystokinin like immunoreactivity are also found in the respiratory tract of various mammalian species. Immunocytochemistry localises bombesin and calcitonin to mucosal endocrine cells; the former are present early during fetal development and increase up to the perinatal stages, when the bombesin content of the mucosal endocrine cells suddenly falls. In contrast cells containing calcitonin are visible only towards the end of gestation and throughout the perinatal period. VIP, PHI, and substance $P$ are present in the innervation of the lung. Nerve fibres carrying substance $P$ and PHI originate primarily in local cell bodies found in the upper respiratory tract and in the vidian nerve innervating the nasal mucosa. Substance $\mathbf{P}$ originates primarily from sensory neurones located in the nodose ganglia of the vagus. VIP and PHI are present mainly in the upper respiratory tract, including the nasal mucosa, the trachea, and main bronchi. Nerves containing these peptides are seen in close association with seromucous glands, blood vessels, and smooth muscle. This distribution, especially that of VIP, is interesting as it fits with the reported actions of VIP, which include vasodilation, muscle relaxation, and secretion of mucus. Abnormalities of nerves containing VIP have been found in certain patients suffering from severe rhinorrhoea. Substance $P$ is distributed more widely throughout the entire respiratory tract, and nerve fibres containing substance $\mathbf{P}$ are found in close association with the bronchial epithelium, smooth muscle, and blood vessels. The innervation of the bronchial airways by VIP and substance $P$ is interesting in view of the effect of these peptides on non-vascular smooth muscle. VIP is a potent muscle relaxant, whereas substance $P$ contracts it. This interplay may be important in asthma: in fact, it has recently been shown that VIP has a muscle relaxant effect both in vivo (inhalation) and in vitro on strip preparations of bronchial muscle.

Abnormalities of the bombesinergic system have been shown recently; in particular, there is a significant depletion of the bombesin content in hypoplastic lungs from children suffering from the respiratory distress syndrome. This finding, together with the facts that there is a considerable amount of bombesin in the developing lung and that bombesin has been reported to have a trophic action, suggests that bombesin may have a trophic role in the human lung. This suggestion is further supported by the finding of bombesin in rapidly growing small cell carcinoma of the lung. Cultures of lung tumours grow faster after the addition of bombesin to the culture medium. Possibly, therefore, in tumours the trophic role of bombesin subserves an "autocoid" function-in that the tumour produces its own trophic regulatory factor resulting in rapid growth.

\section{GENITOURINARY SYSTEM}

Very large concentrations of regulatory peptides, including VIP, substance P, PHI, NPY, and somatostatin have been found in the genitourinary system of both sexes. These regulatory peptides are found in autonomic and sensory nerves. The distribution of nerves containing substance $P$ is interesting in view of the putative sensory role of this peptide. These nerves are found in many sensory areas, including the vagina, the cervix, beneath the epithelium of the bladder, in the ureter, and in the glans penis. VIP and PHI show a parallel distribution. Nerve fibres containing these two peptides are seen in close association with blood vessels-in particular, of the cervical canal and of the corpus cavernosum. Nerve fibres containing VIP are also seen in the smooth muscle of the bladder and uterus and in the lamina propria of the bladder epithelium.

As in the cells of the gastrointestinal tract, these peptides are localised in large, dense, neurosecretory granules quite distinct from the small neurosecretory granules containing the classic neurotransmitters adrenaline and acetylcholine. These "non-adrenergic, non-cholinergic" types of neurosecretory granules have been recognised for almost 20 years. In 1970 they were termed " $p$ " type by Baumgarten because of their resemblance to the peptidergic neurosecretory granules of the central nervous system containing vasopressin and oxytocin. 
The results of preliminary investigations suggest that several regulatory peptides-for example; VIP-are concerned in several genitourinary complaints. Patients with "unstable" bladders have been shown to have a significant depletion of the nerves containing VIP, in particular those of the smooth muscle of bladder. The recognised action of VIP as a potent muscle relaxant may therefore explain the symptoms seen in these patients.

In view of the large concentration of nerve fibres containing VIP around the erectile tissue of the male genitalia a part has been suggested for VIP in male erection. This postulate is supported by the finding of raised concentrations of VIP in the local circulation after induced penile erection, both in man and in animals.

\section{HEART}

Substance P, VIP, and, more recently, NPY have been found in the heart of mammals, including man. Until very recently the neural control of the heart was thought to be mediated by the classic neurotransmitters acetylcholine and noradrenaline. The finding that there are large concentrations of nerves containing NPY in very many structures of the human heart is revolutionising previous concepts of the neural control of cardiovascular function. Nerves containing NPY are found in especially close association with the coronary vessels, the cardiac muscle, and the conduction system.

\section{SYMPATHETIC CHAIN, ADRENAL MEDULLA, AND CAROTID BODIES}

Sympathetic tissue containing catecholamines, including the adrenal medulla and carotid bodies, have been reported to contain regulatory peptides-in particular, somatostatin in the sympathetic chain. The enkephalins have been found in especially large concentrations in the adrenal medulla and carotid bodies. Biochemical evidence indicates the coexistence of amines and regulatory peptides within the same secretory granule. Further support for their coexistence comes from ultrastructural immunocytochemical studies using gold particles of separate sizes to label antibodies to the enkephalins and to dopamine $\beta$-hydroxylase, the converting enzyme in the catecholamine pathway. Ganglioneuroblastomas and phaeochromocytomas have also been reported to produce large concentrations of these regulatory peptides.

\section{SKIN}

The skin is supplied by an intricate system of nerves containing VIP, substance $\mathrm{P}, \mathrm{PHI}$, and also, in lesser concentrations, somatostatin and bombesin. As in many other tissues the histological distribution of these peptidergic nerves fits with their reported sets of actions. Thus substance $\mathrm{P}-\mathrm{a}$ putative sensory peptide-is found in nerves in close association with the epidermis, frequently even penetrating the epidermal layers, whereas VIP is present around sweat glands and blood vessels.

\section{Conclusions}

The unexpected and exciting finding of massive quantities of regulatory peptides present in the so called "diffuse neuro- endocrine system" has revolutionised previously held concepts of control of bodily function. The discovery that very potently acting peptides can be produced by and released from both endocrine cells and neural tissue has generated the concept of integrated functions. This massive system of regulatory peptides is present in all tissues of the body, and the total sum of the endocrine cell mass and the autonomic and sensory nerves, though spread among non-neuroendocrine tissue, is far larger than expected. Pure synthetic peptides are also now available and genetic engineering will soon lead to their mass production by bacteria. The current assay and localisation methods are rapid, accurate, and reliable, allowing the easier interpretation of results.

Recent evidence shows that regulatory peptides are produced from larger precursor forms by a process of post-translation enzymatic cleavage. Some of these supposedly precursor peptides also have biological actions. Greater understanding of these relations has come through use of genetic engineering technology-in particular the isolation of the messenger RNA - to obtain the entire genetic product. In addition, the use of messenger RNA probes to locate cells actively synthesising peptide will permit direct assessment of the synthetic activity of a cell by morphological methods.

Dale's principle has been challenged lately by the finding that a given cell can produce more than one product, each with its independent set of actions. New technical approaches may have to be employed in order selectively to stimulate or suppress the release of each one of the cell products.

Agents are already available which can bind to the receptor site of a specific regulatory peptide (for example, naloxone blocks the enkephalin receptor and proglumide stimulates the cholecystokinin receptors). Others can alter the destruction rate of given regulatory peptides (for example, captopril prevents the conversion of angiotensin I to angiotensin II). Finally, release of peptides can be altered, for example, somatostatin can completely block the release of certain regulatory peptides and capsaicin can cause an acute discharge of substance $\mathrm{P}$. Clearly many more such agents will be discovered and the regulatory peptide system may become a major route of therapeutic intervention in the control of body systems.

Royal Postgraduate Medical School,

Julia M Polak Reader in histochemistry

S R BLoom London W $120 \mathrm{HS}$

1 Gregory RA. Regulatory peptides of gut and brain. Br Med Bull 1982;38: 219-313.

2 Bloom SR, Polak JM. Gut hormones. Edinburgh: Churchill Livingstone, 1981.

${ }^{3}$ Polak JM, Bloom SR. Immunocytochemistry of regulatory peptides. In: N Polak JM, Van Noorden S. Immunocytochemistry-practical applications $\omega$ in pathology and biology. Ch 11. Bristol: John Wright and Son, 1983: 184-211.

\section{Selected references}

Bloom SR, Long RG. Radioimmunoassay of gut regulatory peptides. London: W B Saunders Co Ltd, 1982

Bloom SR, Polak JM, Lindenlaub E. Systemic role of regulatory peptides. Stuttgart: Schattauer Verlag, 1982.

Polak JM, Van Noorden S. Immunocytochemistry-practical applications in pathology and biology. Bristol: John Wright and Son, 1983.

Porter R, Connor M. Substance $P$ in the nervous system. London: Pitman, 1982. (Ciba Foundation Symposium, No 91.)

Said SI. Vasoactive intestinal peptide. New York: Raven Press, 1982. (Advances in peptide hormone research series.)

to

.

